\title{
Optical Line Recognition Sensors for Line Follower
}

\author{
František Šimčák, Michal Kelemen *, Ivan Virgala, Lubica Miková \\ Technical University of Košice, Faculty of Mechanical Engineering, Letná 9, 04200 Košice
}

\section{BIOGRAPHICAL NOTES}

František Šimčák, prof. Ing. CSc. He is a professor of applied mechanics, head of the department of Applied Mechanics and Mechatronics. He is author of 8 monographs, 4 university textbooks, 11 university books and more than 200 publications in journals and conference proceedings at Slovakia and abroads. He received several prizes due to his scientific results.

Michal Kelemen, doc. Ing. PhD. He received M.S. degree in mechanical engineering from Technical University of Košice, Slovakia in 1998 and Ph.D. degree in Mechatronics from Technical University of Košice, Slovakia in 2002. He is an associated professor of the Department of Applied Mechanics and Mecharonics at the Faculty of Mechanical Engineering at the Technical University of Košice, Slovakia. He has been awarded the 1998 "Price of the VolksBank" for the best M.S. graduate and 2007 Price "Scienist of the year". His research interests include mechatronic systems, intelligent robotic systems, dust mass concentration measurement, measurement of non-electric quantities, and microcomputer systems. He has authored more than 180 journal and conference papers on these topics.

Ivan Virgala, Ing. PhD. He received M.Sc. degree in Mechatronics from Technical University of Košice, Slovakia in 2009 and PhD. degree in Mechatronics from Technical University of Košice, Slovakia in 2012. He is a researcher in Department of Applied Mechanics and Mechatronics at Faculty of Mechanical Engineering at Technical University of Košice, Slovakia. He has been awarded by "medal of dean" for excellent study. He is an editorial board member of 3 foreign scientific journals. His research field is design, modeling and control of manipulators, mobile robots, snake robots, humanoid robots and embedded systems. He has authored more than 50 journal and conference papers on these topics.

Ĺubica Miková, Ing. PhD. She received M.S. degree in mechatronics from Technical University of Košice in 2007 and Ph.D. degree in Mechatronics from Technical University of Košice, Slovakia in 2011. She is a researcher of the Department of Applied Mechanics and Mecharonics at the Faculty of Mechanical Engineering at the Technical University of Košice, Slovakia. Her research interests include mechatronics systems and robotics. She has authored more than 45 journal and conference papers on these topics.

\section{KEYWORDS}

Robot, wheeled locomotion, sensor, mechatronics.

\section{ABSTRACT}

Paper deals with optical line recognition sensors, which are useful for line follower robots. Line follower is the category of robotic contests. The basic idea is to locomote with robot and follows the black line on white surface. Robot design is very frequently 
based on two wheeled differentially driven undercarriage with third supporting support wheel. The locomotion of the robot is controlled via using of microcontroller on the base of information from line recognition sensors. Selection of these sensors has a big role in robot design for this category of robot contest.

\section{Introduction}

The basic goal of line follower contest is to locomote and follows the black line on white surface as fast as possible. The winner is who has the shortest time. It seems to be trivial, but there are several complications as obstacle avoiding (brick), open door at the tunnel and passing through the tunnel, passing up and down the ramp and passing through the junction and line interruption and high intensity light (Fig. 1). The designed robot (Fig. 1) is as mechatronic product, which includes actuators, sensors, mechanical parts and electronics with microcontroller. Built robot is currently used as didactic tool for education of mechatronic subjects. Also students can arrange competition as very good motivation $[1,2,3]$.
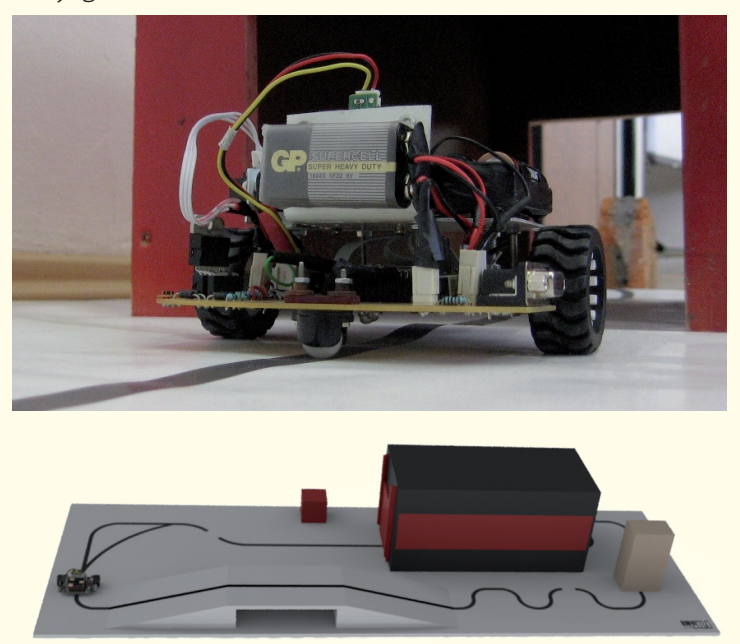

Fig. 1: Linefollower robot with competition race.

Robot motion (Fig. 2) based is on differential driving. It can be characterized as motion on circular arcs around the ICR - Instantaneous Centre of Rotation. Radius of this arc is marked as $R$. Radius of rotation can be calculated from known wheel velocities i.e. $v_{L}$ left wheel velocity and $v_{R}$ right wheel velocity:
$R=\frac{L}{2} \cdot \frac{v_{R}+v_{L}}{v_{R}-v_{L}}$

Instantaneous translation velocity of the robot middle point $P$ can be obtained as:

$v_{P}=\frac{v_{R}+v_{L}}{2}=R \cdot \frac{\omega_{R}+\omega_{L}}{2}$

Angular velocity of robot rotation around the robot middle point $P$ is defined with equation:

$\omega_{P}=\frac{v_{R}-v_{L}}{L}=R \cdot \frac{\omega_{R}-\omega_{L}}{L}$

Robot locomotion can be described through the translation velocity $v_{p}$ and rotation angular velocity $\omega_{p}$, which are defined with previous kinematic transformations (2) and (3).

Robot position is defined with two position variables $\left(x_{p}\right.$ a $\left.y_{p}\right)$ and with directional variable $\left(\varphi_{p}\right)$ :

$$
\begin{aligned}
& \dot{x}_{P}=v_{P} \cdot \cos \phi_{P} \\
& \dot{y}_{P}=v_{P} \cdot \sin \phi_{P} \\
& \dot{\phi}_{P}=\omega_{P}
\end{aligned}
$$

Non-holonomic constrain can be obtained from the previous equations (4). This constrain must be accepted with path planning unit:

$\dot{y}_{P}=\dot{x}_{P} \cdot \tan \phi_{P}$

Robot moves straight if both wheels rotate with the same angular velocity (it means that $R \rightarrow \infty$ ). Robot rotates around the middle point if wheels rotate with the same velocity but different rotation direction (it means that $\mathrm{R}=0)[2,4]$.

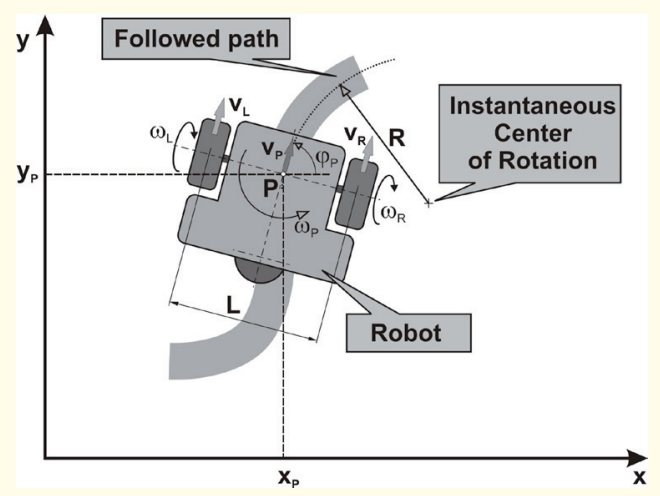

Fig. 2: Navigation task and locomotion in coordinate system. 


\section{Problem Definition}

The first problem is to eliminate the influence of the day light to line recognition sensors. Consequently, infrared reflective optocouplers with day light filter are selected. These optocoupler are consisting of infrared LED diode as light source and infrared phototransistor as light detector. Light emitted from LED diode reflects from surface and returns back to phototransistor. Light intensity of reflected light depends on surface color (white surface or black line).

Next problem is high intensity lamp placed near the followed line. It causes the changed light conditions. The similar problem is passing through the dark tunnel.

Another problem is passing up and down the ramp. Uphill and downhill slope cause the change of the distance between the sensors and sensed surface. The problem is right at the start and end of the slope, where distance between the sensors and surface rapidly changes.

Previous mentioned problems show the importance of the line recognition sensors. Also geometry of sensor arrangement plays the significant role. Finally the sensor data processing and evaluation are also needful.

Next part of the paper is devoted to testing of selected sensors. The question is: Which sensor are the best for line recognition sensing.

\section{Testing of the Line Recognition Sensors - Selection of Sensor}

Three various type of reflective infrared sensor (QRD1114, LTH209-1, CNY70) have been tested in order to choose suitable line recognition sensor (Fig. 3). All tested sensors are designed as infrared reflective optocoupler with daylight filter.
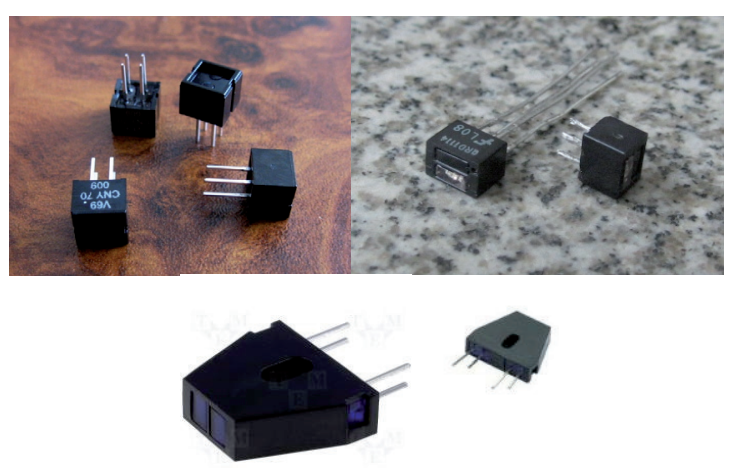

Fig. 3: Tested infrared line recognition sensors.
All sensors have been attached on movable oneaxis table with increment $1 \mathrm{~mm}$ during testing with white reflective target area (Fig. 4). Distance of sensors has been changed in range $0-20 \mathrm{~mm}$. Collector current of every tested sensor has been observed during the daylight, halogen light and dark environment. The aim of this testing was to find, which sensor has minimum sensitivity to changed light intensity of environment [1].

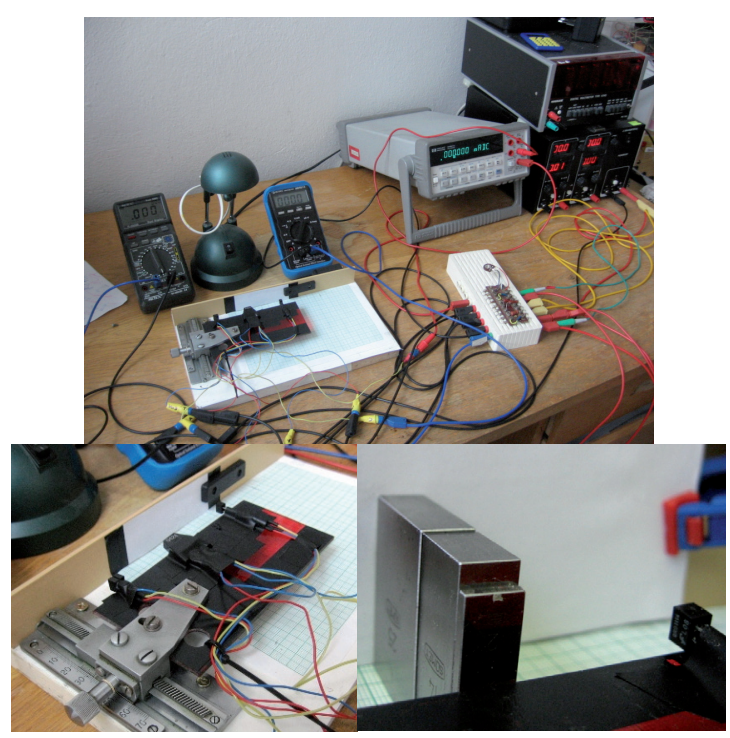

Fig. 4: Testing of various type of line recognition sensors.

Fig. 5 shows results of testing. QRD 1114 sensor has the best properties from tested sensors. QRD 1114 has larger collector current then other tested sensors. Useful range of distance for line recognition is $10 \mathrm{~mm}$. Consequently, QRD 1114 has been selected for the robot. In order to analyze the performance and characteristics of this sensor, two different sensors QRD 1114 were tested using different surface colors, white and black. White and black were chosen as these are the two colors utilized in the competition for the line follower. Two different sensors were tested in order to find out the level of variation between sensors, and to as certain each sensor would require individual adjustment to gain the correct readings (Fig. 6). The two sensors which were tested were from the same batch that had already been installed on the robot. In order to test the sensors a bench setup was created using a 1 axis table with increments of $1 \mathrm{~mm}$.

As it is visible from the graphs (Fig. 8), both sensors give slightly different values for the same dis- 
tances. In order to end up with similar results for both sensors on the line following robot, we will require adjustable potentiometer dividers, so we can change the value between logical 1 and logical 0.
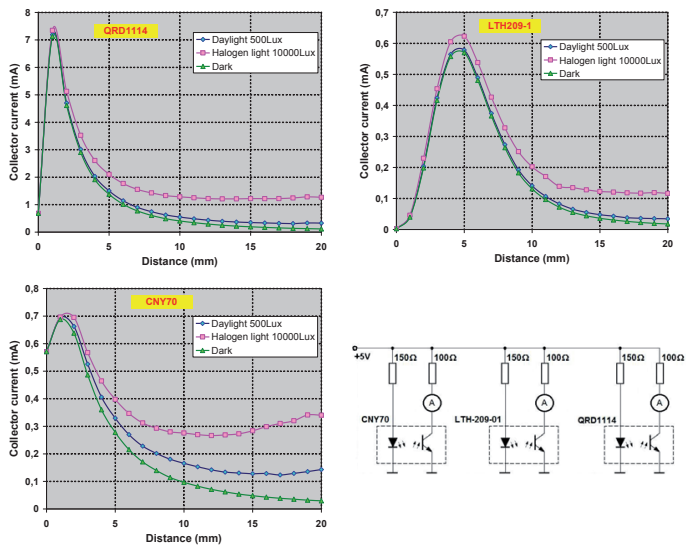

Fig. 5: Results of line recognition sensors testing.
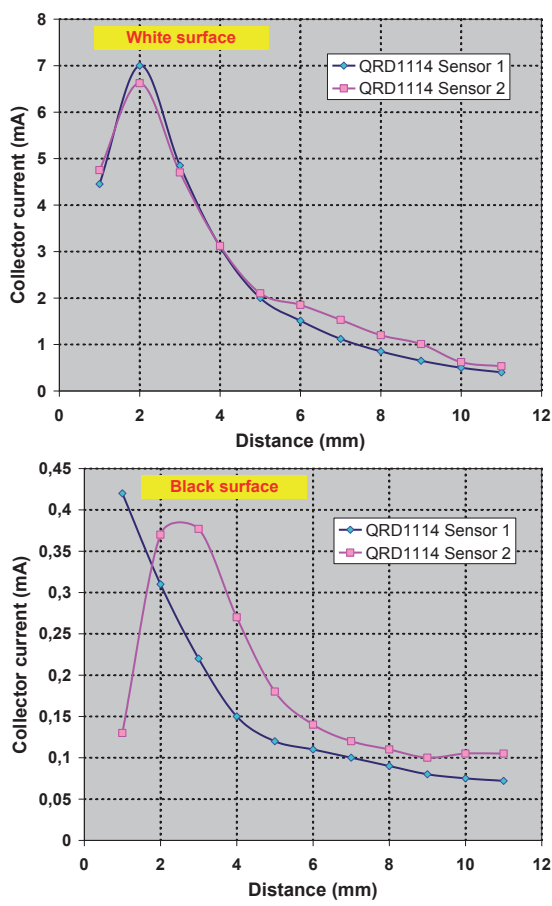

Fig. 6: Results of comparative testing of two samples of $Q R D 1114$.

\section{Line Recognition Sensors Issues with Ramp}

By moving the sensors ahead of the axis of rotation of the robot a relatively small increase in positional angle of the robot can be detected with ease, this in turn leads to less radical position ad- justments which can cause the robot to lose the line. Instead it enables small gradual corrections to be made.

Moving the sensors in front brings its own problems regarding clearance with the ramp (Fig. 7). If the sensors would be moved further in front of the robot, they would still be required to clear the ramp. A too small a distance between the surface and the sensors would result in incorrect feedback, and the robot might enter the ramp at the wrong angle and risk falling off the side $[1,2,3,4]$.

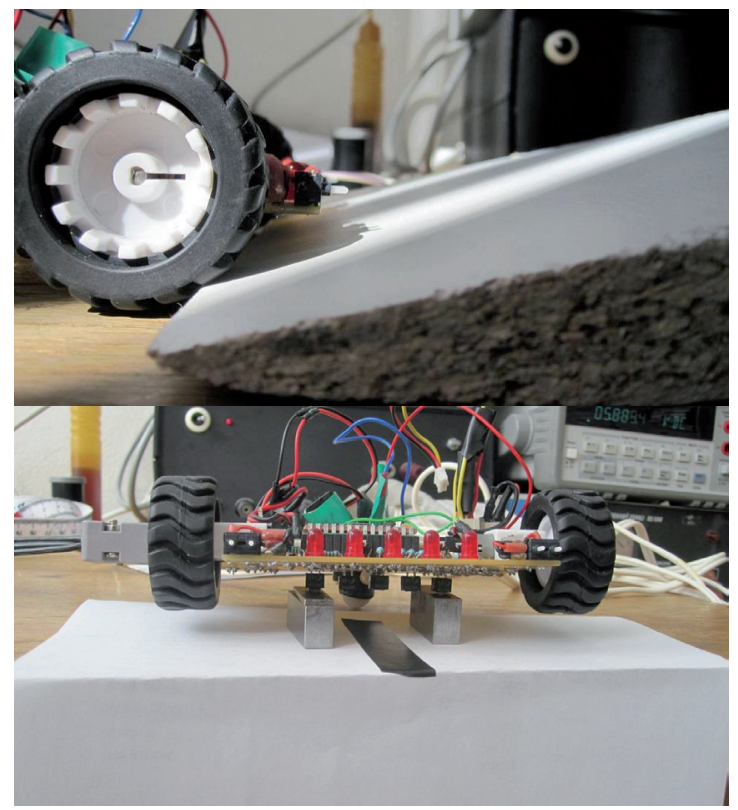

Fig. 7: Line recognition sensors issues with ramp and testing of line recognition sensor.

So in order to avoid this issue the sensors would need to higher off the ground, which in turn can lead to problems as the sensor can only register up to a certain distance effectively.

This distance was measured using block gauges, using the SEROUT command of basic atom to measure the value. The measurements (Fig. 7) were taken at 600 Lux light intensity. The values measured are determined by the 10 bit resolution AD converter integrated in controller. The 5 Volt range is divided into 1024 steps, which equates into 0.004 $\checkmark$ per step.

We decided that up to $17 \mathrm{~mm}$ between the sensors surface and the reflective surface would be the maximum, as the difference between black and white was becoming smaller and smaller and 
we would need to be able to tell what was black and white accurately (Fig. 8).

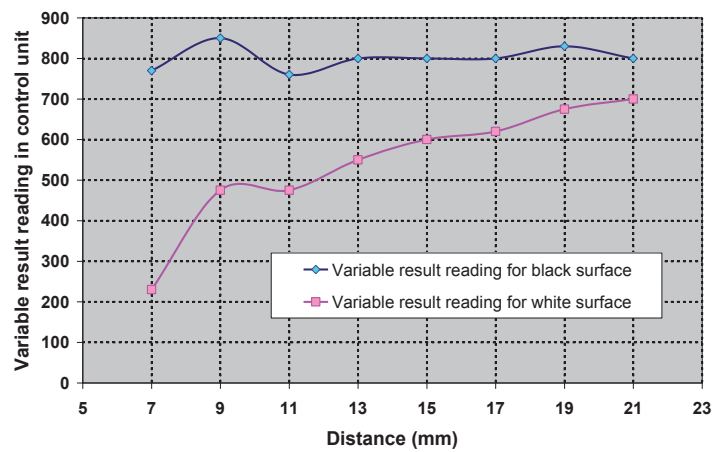

Fig. 8: Results of distance measurement of line recognition sensor with control unit.

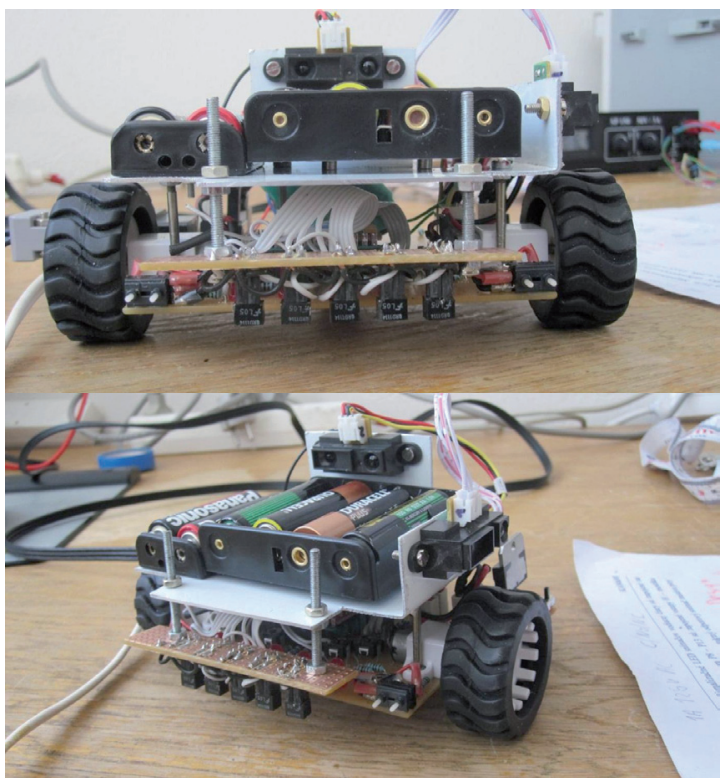

Fig. 9: The new position of line recognition sensors.

Instead of using logical conditions to determine whether or not there was a line under any of the sensors we now required a new set of conditions consisting of a nominal value under which we could say it was definitely white and another value we could say it was definitely black. The final calibration using the potentiometers for each sensor the overlap between positively identifying white or black was only 50 points, anything above 650 was definitely black and anything below 600 definitely white.

The new position for the sensors (Fig. 9) was hung off the new battery holder bracket, with the option of adjusting height if required, it was set at $15 \mathrm{~mm}$ above the surface to start with.

\section{Conclusion}

The topic of this paper seems to be easy but several key issues raised up on prototype of the robot. That is a typical example, that also design of simple product can has also many problems. Practical experiences are very important for students, because students are better prepared for practice. That is something what is not possible to learn from books. Consequently, practical exercises bring skills and experiences to students $[5,6]$.

\section{Acknowledge}

The authors would like to thank to Slovak Grant Agency - project APV-0091-11, VEGA 1/1205/12. This contribution is also the result of the project implementation: Research of modules for intelligent robotic systems (ITMS: 26220220141) supported by the Research \& Development Operational Programme funded by the ERDF.

\section{References}

[1] Kelemen, M., Colville, D. J. Kelemenová, T., Virgala, I. Miková, L.: A Concept of the Differentially Driven Three Wheeled Robot / - 2013. In: International Journal of Applied Mechanics and Engineering. Vol. 18, no. 3 (2013), p. 687-698. - ISSN 1734-4492

[2] Jurisica, L., et al. (2005): Robotics. Slovak Technical University, Fac. of Elec. Eng., Bratislava, 2005. 134 pages

[3] Kacir, K. (2011): Design of functional three wheel vehicle with navigation in unknown environment. Ms Thesis, Technical university of Kosice, Fac. of Mech. Eng., 2011, Kosice, 62 pages

[4] Mikova, L., Trebuña, F.: The Application of Simulation Methods for Modeling Mechatronic Systems. Acta Mechanica Slovaca. Vol. 16, No. 2, 2012, pp. 32-37. ISSN 13352393

[5] Nitulescu, M.: Experiments in Mobile Robot Control. Mechatronics 2008. Paper \#200. Available online. 2008) Cited 04-07-2013. http://www.mecatronica.pub.ro/romar/ articole/mecatronics2008_200.pdf

[6] Vitko, A., Jurišica, L., Babinec, A., Duchoň, F., Klúčík, M.: Some Didactic Aspects of Teaching Robotics. In: AT\&P Journal Plus. ISSN 1336-5010. No. 2. Robotics in education (2010), pp. 109-112.

[7] Ivančo, V., Dovica, M., Gorzás, M.: In-Pipe Machine and Principles of its Motion and Control. Acta Mechanica Slovaca. Vol. 14. No. 2., 2010. pp. 66-70. ISSN 1335-2393.

[8] Dekan, M., Duchoň, F., Jurišica, L., Vitko, A., Babinec, A.;: iRobot Create Used in Education. In: Journal of Mechanics Engineering and Automation. ISSN 2159-5275. Vol. 3, Iss. 4 (2013), s. 197-202.

[9] Koniar, D., Hargaš, L., Hrianka, M.: Application of standard DICOM in LabVIEW. Proc. of 7th conf. Trends in Biomedical Engineering, Kladno 11. - 13. 9. 2007 ISBN 978-8001-03777-5. 2007.

[10] Hargaš, L., Hrianka, M., Koniar, D., Izák, P.: Quality Assessment SMT Technology by 
Acta Mechanica Slovaca

Journal published by Faculty of Mechanical Engineering - Technical University of Košice

Virtual Instrumentation. Applied Electronics 2007, Pilsen, 5. - 6. 9. 2007, ISBN 987 80-7043-537-3, 2007.

[11] Gmiterko, A., Virgala, I., Vacková, M.: Dynamic Analysis of Two-Mass System to Imitate Rectilinear Motion of a Snake. Acta Mechanica Slovaca. Vol. 14. No. 2. pp. 74-81 ISSN 1335-2393.

[12] Duchoň, F., Dekan, M., Jurišica, L., Vitko, A.: Some Applications of Laser Rangefinder in Mobile Robotics. In: Journal of Control Engineering and Applied Informatics. - ISSN 1454-8658. - Vol. 14, №. 2 (2012), s. 50-57

[13] Gmiterko, A., Kelemen, M., Kelemenová, T., Miková, L.: Adaptable Mechatronic Locomotion System. Acta Mechanica Slovaca. Vol. 14. No. 2. 2010. pp. 102-108. ISSN 1335-2393.

[14] Trebuňa, F., Šimčák, F., Handbook of experimental mechanics. 1st edition. Košice :TU of Kosice, Fac. Of Mech. Eng. 2007. 1526 pages. ISBN 970-80-8073-816-7.

[15] Hanzel, J., Duchoň, F., Rodina, J., Pásztó, P.: Global Navigation Systems for Mobile Robots. In: International Journal of Systems Applications, Engineering \& Development. - ISSN 2074-1308. - Vol. 7, Iss. 5 (2013), s. 279-285.

[16] Ostertag, 0., Ostertagová, E.: Measurement of tensions for 2-D orthotropic environment with the photostress method. 2006. In: Acta Mechanica Slovaca. Vol. 10, №. 1 (2006), pp. 369-376. ISSN 1335-2393.

[17] Tölgyessy, Michael - Chovanec, Luboš - Pásztó, Peter - Hubinský, Peter: A Plane Based Real-Time Algorithm for Controlling a Semi-Autonomous Robot with Hand Gestures Using the Kinect. In: International Journal of Imaging and Robotics. - ISSN 2231525X. - Vol. 13, Iss. 2 (2014), s. 126-133.

[18] V. Baláž, E. Ostertagová, D. Palašcáková. Using of e-learning for teaching extension at KVTaR Acta Mechanica Slovaca. Vol.. 10, No. 2-A (2006), pp. 47-50. - ISSN 13352393. 2006. 